\title{
The highway to hooliganism? An evaluation of the impact of combat sport participation on individual criminality
}

\author{
Craig Jenkins and Tom Ellis ${ }^{\dagger}$ \\ (Both) Institute of Criminal Justice Studies, University of Portsmouth, St George's Building, \\ 141 High Street, Portsmouth, Hampshire, PO1 2HY. \\ †(Corresponding author) Email: tom.ellis@port.ac.uk
} Submitted 26 January 2011; accepted 3 February 2011

Keywords: combat sport, criminality, risk factors, violent offending, antisocial behaviour

Craig Jenkins was a criminology and sociology undergraduate at the University of Portsmouth. He graduated with first class honours. His dissertation, on which this research is based, was part of the course requirement. He has also been involved in martial arts since his early teens.

Tom Ellis is a principal lecturer at the Institute of Criminal Justice Studies, University of Portsmouth. His areas of expertise include Japanese criminal justice, youth justice, prisons, prostitution and trafficking. He sits on the Child Exploitation and Online Protection Centre's Research Advisory Group. Until 1999, he worked for the Home Office Research, Development and Statistics Directorate and also had a two-year spell at the United Nations Interregional Crime and Justice Research Institute, based in Rome.

\footnotetext{
Abstract

The aim of this research was to evaluate whether combat sport has an impact on participants' criminality, and if so, whether combat sport is appropriate for use in offender treatment programmes and crime reduction strategies. The paper first provides a comprehensive summary review of the existing evidence on the relationship between crime and sports participation in general,
}

and then on crime and combat sports in particular. The paper then presents and discusses findings from new primary research designed to address the issues raised in the review. A semistructured questionnaire, combining Likert scale items and open questions, was issued to 50 individuals who regularly trained at two different combat sports facilities. The research was designed to assess the relationship between combat sports participants and commonly experienced sociocultural and individual risk factors. Based on the findings, we argue that participation in combat sports can distance individuals from nonstructural risk factors in behavioural, community / social and economic spheres. Detachment from risks in these areas makes combat sport potentially appropriate for use within interventions aimed at: violent offenders; those who offend in groups; emotionally impulsive offenders; and as a moderator of antisocial behaviour. However, further research is required to understand fully the impact of such interventions.

\section{INTRODUCTION}

This UK study is concerned with whether and how combat sports, such as martial arts and full contact fighting sports such as boxing, affect the potential criminality of
International Journal of Police Science and Management, Vol. 13 No. 2, 2011, pp. 117-131 DOI: $10.1350 /$ ijps.2011.13.2.234 
participants. This was accomplished using principles derived from cognitive behavioural treatment and risk factor-based intervention, which has seen a rapid growth of interest, following the passing of the Crime and Disorder Act 1998 (CDA 1998).

The CDA 1998 contained a series of crime tackling policies aimed directly at young offenders and the general youth population (Muncie, 1999, p. 147). Identification of risk factors featured as a crucial element of the CDA 1998, with the primary focus on: poor parental supervision; poor discipline; truancy; and unstable homes (Home Office, 1997 p. 5). The Youth Justice Board (YJB), constituted under the CDA 1998, additionally included low income and aggressive behaviour (Anderson et al., 2005 p. 4). These risk factors relate primarily to: family; school; community; and personal experiences (Anderson et al., p. 3). The YJB's crime reduction strategy therefore relied heavily on both community-based crime prevention schemes and offender treatment programmes.

Between 1999 and 2002, the YJB implemented 42 intervention schemes costing over $£ 4.5$ million. Eight of these interventions (involving 3,350 youths) were sport/physical activity/leisure-based (Hurry \& Moriarty, 2004 pp. 4-20). Additionally, sport-based interventions are being implemented across the UK, including: Positive Futures; Police Community Boxing Clubs; Sport in the Community; Sport England; Splash/Splash Extra; and Midnight Basketball. However, with the exception of Police Community Boxing Clubs, there appears to be no inclusion of combat sports within the schemes despite their increasing popularity. Mixed Martial Arts (MMA), otherwise known as cage fighting, is widely considered to be the fastest growing sport in the world, grossing over US $\$ 200$ million in 2007, with an impressive list of celebrity fans, and gaining increased popularity in many countries, including the UK (Davies, 2008). Given the popularity and spread of modern and traditional combat sports, the need for our study is perhaps overdue. First, however, it is important to summarise the relevant existing evidence.

\section{SPORTS PARTICIPATION AND CRIME REDUCTION}

Recent research has suggested that those involved in structured and supported leisure activities are less likely to take part in antisocial behaviour and offending (Mahoney \& Stattin, 2000, p. 123). Conversely, those involved in activities lacking structure and support are at the highest risk of engagement in young offending, and have the most deviant peers (Abbot \& Barber, 2007, p. 59; Mahoney \& Stattin, 2000, p. 123; Mahoney, Stattin, \& Magnusson, 2001, p. 509). Furthermore, this is particularly important for reducing youth crime in rural areas (Meak, 2006 pp. 100-101). As noted, sports- and physical activity-based interventions have featured heavily in tackling youth crime and antisocial behaviour. Offering outdoor sports such as canoeing as an incentive to enrol in life skills workshops, Fairbridge projects represented five of the YJB's eight sports and physical activity programmes between 1999 and 2002 (Astbury, Knight and Nichols 2005, pp. 8485). The others included the Duke of Edinburgh's Award and two Midnight Basketball programmes (Hurry \& Moriarty, 2004, pp. 4-20). In an impact evaluation of all 42 YJB intervention programmes, Hurry and Moriarty (p. 58) found a 25 per cent reduction (ie, a 60 per cent reoffending rate) in reoffending compared with the year before enrolment. However, there was no comparison group available to establish evidence of a significant benefit (Hurry \& Moriarty, p. 58). Indeed, the small number of evaluations relevant to UK sports programmes 
Table 1: UK sport-based crime reduction scheme summary

\begin{tabular}{|c|c|c|}
\hline Programme & Programme structure & Evaluation outcome \\
\hline Fairbridge Programme & $\begin{array}{l}\text { Outdoor sports participation limited } \\
\text { to } 1 \text { st week } \\
\text { - Eg, climbing and canoeing for the } \\
\text { initial week. } \\
\text { Then opportunity to enrol in: } \\
\text { - outdoor pursuit courses } \\
\text { - life-skills workshops }\end{array}$ & $\begin{array}{l}\text { - No evidence of a long-term crime } \\
\text { reduction } \\
\text { - Reduced the circumstances which } \\
\text { put youths at risk of offending } \\
\text { - Sport played a vital role in fostering } \\
\text { pro-social relationship with } \\
\text { programme supervisors and catalyst } \\
\text { for personal development (Astbury, } \\
\text { Knight, \& Nichols, 2005) }\end{array}$ \\
\hline $\begin{array}{l}\text { Midnight Basketball (The } \\
\text { original United States } \\
\text { programme) }\end{array}$ & $\begin{array}{l}\text { - Basketball leagues set up between } \\
10 \mathrm{pm} \text { and } 2 \mathrm{am} \text { in inner city areas } \\
\text { in the United States }\end{array}$ & $\begin{array}{l}\text { - Cities with midnight basketball } \\
\text { schemes showed significant } \\
\text { decreases in crime rates (inc. } \\
\text { property and violent crime) } \\
\text { (Hartmann \& Depro, 2006) }\end{array}$ \\
\hline
\end{tabular}

can be regarded as indicative rather than definitive, as shown in Table 1.

Examples of other sports-based interventions include: 'Summer Splash' schemes, using sports such as kayaking and football (Loxley, Curtin, \& Brown, 2002, p. 8); Sport England and Best Value through sport initiatives (Sport England, 1999); summer camp programmes including baseball, basketball and field hockey (Haynes, Rife, \& Laguna, 2005, p. 41); Police Community Boxing Clubs (Metropolitan Police Service, n.d.); Positive Futures (Ramella, as cited in Smith \& Waddington, 2004, pp. 281-282); the West Yorkshire Sports Counselling Association; and the Hafotty Wen 14 peaks programme (Nichols \& Crow, 2004, p. 273). Additionally, Sport England and local authorities have provided sport-based community regeneration schemes in deprived areas (Neighbourhood Renewal Unit, 2003), resulting in the development of the Tuckingmill Skate Park in 2004 (Sport England, 2005, p.15) and the X-site Skate Park, Skegness, boasting a 17 per cent reduction in reported crime since opening in 2006 (Sport England, n.d.a, pp. 11-12).

\section{THEORETICAL UNDERPINNINGS OF SPORTS INTERVENTIONS AND THEIR CRITICS}

The theoretical understanding of how such sports programmes might reduce crime can be summarised as follows:

- Cathartic: all sport entails elements of violence that releases and channels aggression that would otherwise lead to violent crime and therefore educates 'men' into conscious and responsible self-control (Lorenz as cited in Dunning, 2005, p. 905).

- Diversionary: diverting youths away from time spent committing crime (Nichols, 1997, p. 183; Nichols \& Crow, 2004, pp. 269-270).

- Providing natural excitement: sating individuals' quest for excitement otherwise quenched through crime or drugs (Nichols, p.183; Coalter, and Elias \& Dunning, both studies as cited in Smith \& Waddington, 2004, p. 284).

- Developing cognitive competencies: contributing to increased self-esteem, self-control and a sense of achievement, 
also linked to increased employability (Loxley et al., 2002 p.10; Nichols, pp. 185-187; Nichols \& Crow, p. 270).

There are inevitably critics. Smith (as cited in Dunning, 2005, p. 910) argues that sport can facilitate violent behaviour since participants are trained to see opponents as non- human. Feminist treatments of aggressive sports as a method of crime reduction have also been critical. Table 2 outlines the key findings from studies, all from the USA, arguing that participation in aggressive sports increases 'violent masculinities'.

It would seem then, that from the research summarised in Table 2, increased

Table 2: US research on the negative impact of aggressive sports participation

Study
$\begin{aligned} & \text { Hoffman (as cited in } \\ & \text { Dunning, 2005, p. } 911\end{aligned}$
$\begin{aligned} & \text { Koss and Gaines (1993, } \\ & \text { pp. 94-108) }\end{aligned}$
pp. 94-108)

Nelson (as cited in Dunning, 2005, p. 911)

Crosset, Benedict, and McDonald (as cited in Dunning, 2005, p. 911); Woods (2007, p. 295)

Forbes, Adams-Curtis, Pakalka, \& White (2006, pp. 447-455)
- 107 cases of sexual assault.

- In 10 division 1 schools 1991-1993.

- Analysed police records, judicial affairs and reports.

- 147 males at private, Midwestern university inc. 101 aggressive sport athletes (football, basketball, wrestling and soccer).

- Analysed self-reported: relationship aggression and coercion, sexism, rape myth and violence acceptance, and attitude toward homosexuals.
Findings

- Football \& basketball 38\% more frequently involved in sexual assault.

- Basketball \& football players were significantly more likely to be sexually aggressive (inc. males involved in other sports).

- Alcohol use \& athletic participation were two of four variables accounting for $11 \%$ variance in levels of sexual aggression.

- Athletes were $16 \%$ of campus population.

- Commit 55\% of acquaintance rapes in 1991.

- Commit 33\% of 862 sexual assaults on campuses over three years in 1980s.

- Male athletes were 3\% of campus population.

- Commit $19 \%$ of sexual assaults \& $35 \%$ of domestic assaults.

- Basketball players show disproportionately high number of sexual assaults.

- Aggressive sports participants committed more psychological and physical aggression (inc. injury to partners) \& sexual coercion of partners.

- Also more sexist and hostile towards women, accepting of violence, less tolerant of homosexuality. 
contact and aggression in sports can only lead to more violence and crimes against women. Inevitably, there are also criticisms that could be levelled at these findings. First, feminist studies have failed to account for the effects of aggressive sports on female participants. They focus only on sports that have a predominantly male following and male sports teams, ignoring aggressive contact sports with female participants or competitive female sports teams.

Second, the sports selected in the studies in Table 2 are subject to interpretation regarding aggression and contact. For example, American football is rightly regarded as aggressive. Much like rugby, its fast paced and unavoidable physical contact makes an 'aggressive' classification appropriate. However, basketball is a non-contact sport. Players are only allowed to make contact with the ball, not another player's body. Physical violence occurs as a result of the unsporting character of the rule breaker. Similarly, excessive physical contact in soccer results in a foul; it is not a licit feature of the game. These criticisms therefore lead us on to a consideration of the main focus of our study: combat sports.

\section{COMBAT SPORTS}

This study focuses on sports which encompass a regular and unavoidable engagement in interpersonal violence, aggression and contact, ie, combat sports. This pushes our focus to an extreme end of the sports spectrum, but one that therefore reduces ambiguity when interpreting what constitutes a violent or aggressive sport.

Only a handful of US and European studies have given consideration to combat sport and crime reduction, which remains an under-researched area. Table 3 provides a summary of the key studies and their findings.

From these studies, it is clear that the field is under-researched and there is no reliable of comprehensive picture. Wright's (2006, pp.158-171) in-depth approach has provided the most comprehensive list of benefits, in this case, for boxing training participants.

The positive benefits of combat sports are also found in Fletcher's (as cited in Nichols, 1992, p. 184) and Palermo et al.'s (2006) studies. In Fletcher's case (where less is known about the detail of the study), emotional control was gained through boxing, while for Palermo et al. (p. 654), when taught appropriately, martial arts could be effective in reducing problem behaviour.

Trulson's (1986) study is the most nuanced and perhaps the most important in thinking about the type of approach to combat sports that would be most appropriate for interventions with offenders. It was clear that the traditional philosophical and psychological elements were vital to being effective in reducing risk factors associated with offending. If these elements were removed, Trulson (p. 1131) found that combat sport was associated with increased criminal behaviour. Consider the role of the referee in traditional compared with nontraditional combat sports. Those participating in MMA will continue to strike an unconscious opponent until the referee intervenes, whereas a traditional martial artist shows control, using only the necessary amount of force to win a bout.

Another significant challenge comes from a different perspective. Endresen and Olweus's (2005) study represents the strongest challenge to the use of combat sports to reduce criminal behaviour since they found that fighting sports could increase criminality among untroubled youths. From an interventions perspective, this can be seen as analogous to 'overdosing' minor offenders with interventions, which is known to be likely to increase their criminal behaviour. Endresen and Olweus therefore pose the 
Table 3: Summary of research on the effects of combat sport participation

\begin{tabular}{|c|c|c|}
\hline Study & Sample/Method & Findings \\
\hline $\begin{array}{l}\text { Trulson (1986, p. 1131) } \\
\text { (USA) }\end{array}$ & $\begin{array}{l}\text { - } 34 \text { male school students identified } \\
\text { as delinquent by the Minnesota } \\
\text { Multiphasic Personality Inventory } \\
\text { (MMPI) \& Jackson Personality } \\
\text { Inventory (JPI) - repeated } \\
\text { measures. } \\
\text { - Group 1: traditional taekwondo } \\
\text { lesson 3×1 hour/per week, for } 6 \\
\text { months. } \\
\text { - Group 2: same as group } 1 \text { but } \\
\text { modern adaptation, lacking } \\
\text { philosophical elements } \\
\text { - Group 3: no intervention. }\end{array}$ & $\begin{array}{l}\text { - Group 1: decreased aggression and } \\
\text { anxiety, increased self-esteem \& } \\
\text { value orthodoxy } \\
\text { - Group 2: large increase in } \\
\text { aggressive behaviour observed } \\
\text { - Group 3: No change in any } \\
\text { personality measures. }\end{array}$ \\
\hline
\end{tabular}

Fletcher (as cited in Nichols, • Unknown number of amateur 1997, p. 184) (UK)

Endresen and Olweus (2005, pp. 468-476) (Norway)

Palermo et al. (2006, pp. 656-659) (Italy) boxers (gender unknown) in unpublished study of amateur boxing club.

- Observations and interviews.

- 477 male school students with varied participation in combat sports: boxing; kickboxing; wrestling; karate; judo \& taekwondo.

- 3 groups of participants

- 1 group of non-participants violence and total antisocial involvement test
- Before, during \& after measures: self-reported antisocial behaviour,

- 13 male and 3 female children aged 8 to 10 , diagnosed with behavioural problems associated with delinquency.

- Group 1 enrolled on a 10-month karate programme: 3 lessons per week.

- Group 2: no intervention.

- Before \& after measures of intensity, adaptability and mood regulation

Wright (2006, pp. 149-171) (USA)
- Unknown number of male youths from boxing clubs in impoverished areas of New York \& San Francisco.

- Interviews \& observations to measure boxing's potential to reduce violence in the community.
- Participants less likely to engage in street violence due to increased self-esteem and self-control

- Untroubled boys become more prone to violent and non-violent antisocial behaviour changes: fights (inc. weapons) truancy and vandalism

- Negative effects persisted long after participation ceased.

Participating youths showed greatly improved behaviour.

- Observed a diversion from potentially criminal behaviour, eg, disobedience and aggressive temperaments.

- Identified 10 effects of boxing associated with reduction in violence and crime (details in text). 
Table 4: Wright's (2006) 10 benefits of boxing training

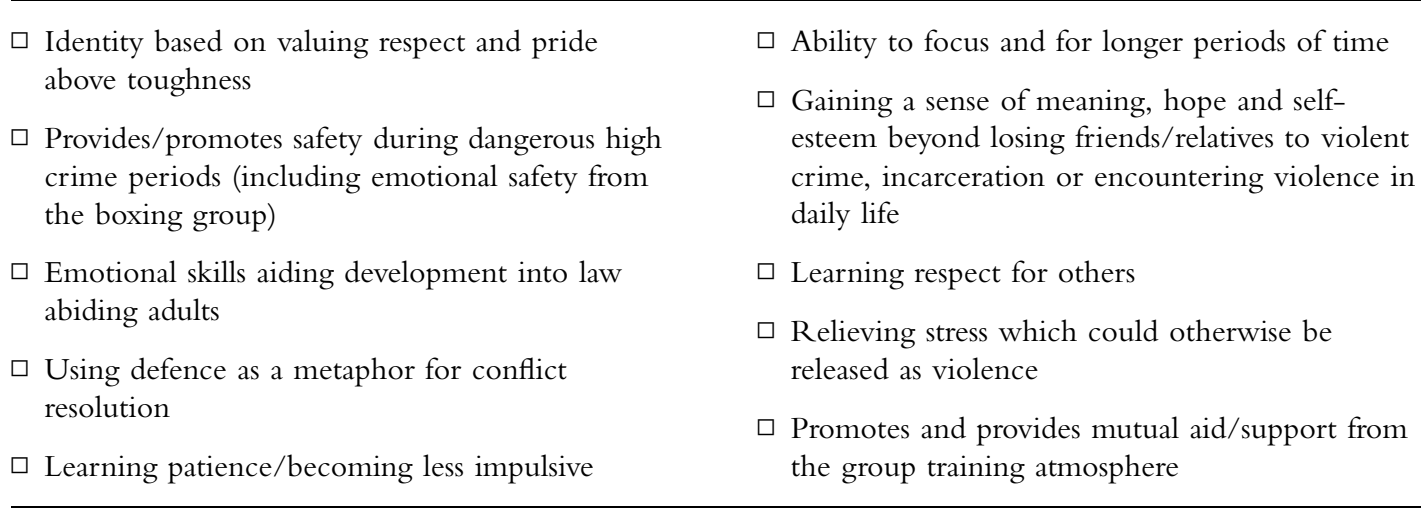

intriguing question of whether those without criminal involvement should be participating in combat sports.

It seems that sport- and recreation-based crime reduction strategies have some theoretical and empirical, if contested, justification. However, not much attention has been given to justifying the use of combat sport-based interventions. First, little is known about the effects of varying styles of combat sports which vary in levels of aggression, interpersonal contact and machismo. Second, there is little research aimed at the effects of combat sport participation on grown adults of both genders, as the focus is nearly always on male youths. Paradoxically, because of the ethical issues (not to mention bureaucracy) involved in researching those under 16 years, our focus is exclusively on adults. Finally, there has been little focus on how continued combat sport participation can address the needs of those at risk of criminality through 'values of sport' (Sport England, n.d.b) such as educational/economic benefits and community inclusion. Given the paucity of research and the level of potential dissonance in the results, we felt it was timely to carry out our own investigation. Importantly, our research is the first we are aware of to include male and female participants. In order to address what we see as the weaknesses of much of the feminist perspective research on the negative impact of 'contact' sports, we also evaluate the relationship between socio-cultural areas of risk and voluntary participation in sports, where the distinction between 'contact' and 'noncontact' is extremely clear.

\section{METHODOLOGY}

We carried out our research during the spring of 2009 in a coastal city in the UK on two combat sport clubs. The first author was able to negotiate access through his active participation in combat sport, providing a hitherto unique perspective. Participants completed questionnaires anonymously at the two clubs' training facilities during training sessions.

The semi-structured questionnaire included 7-point Likert scale statements and some qualifying open questions. The former were designed to measure the impact of combat sports on the potential risk factors experienced in areas of everyday life. The latter were designed to allow the respondent to expand on the reasons for a particular response to the Likert statements. The Likert component of the questionnaire produced a very respectable Cronbach's Alpha reliability score of 0.718 . 
We gathered a sample of 50 regular participants from the two clubs. While club records were not sufficient to carry out a systematic sampling exercise, the numbers involved compare favourably with many of the previous studies most commonly referred to in this area, some of which do not even include the number of subjects. The clubs practised different approaches, with one using traditional Korean Taekwondo (similar to Karate) while the other used the hybrid sport of K1, ensuring a variation in combat sports. K1 combines training in multiple traditional fighting styles, and therefore was selected to represent the majority of the sample. However, in $\mathrm{K} 1$ the spiritual aspects of the training styles are removed, leading one to question its potential to decrease criminal tendencies in participants (Trulson, 1986, p.1131). We ensured that 20 per cent of the sample was female, both to match the overall gender balance in the two clubs, and to address the absence of females in the existing studies. Table 5 summarises the sample characteristics.

Participants' ages ranged from 16 to over 40 with 44 per cent of the sample between 21 and 30 years of age. 60 per cent participated for between two and six hours a week in combat sports. Overall participation ranged from one to ten hours per week. 58 per cent had been training at their respective club for between one and ten years, and the remainder for under a year. 64 per cent of respondents had had alternative combat sport experience, 14 per cent of

Table 5: Sample characteristics by gender and club

\begin{tabular}{lccc}
\hline & Male & Female & All \\
\hline K1 Club & 24 & 9 & 33 \\
Taekwondo Club & 16 & 1 & 17 \\
Total & 40 & 10 & 50 \\
\hline
\end{tabular}

whom had experience in five or more alternative combat sports. Taking these points into consideration, the sample represents a relatively wide range of combat sport participants.

\section{RESULTS}

The results are presented under headings representing the major four categories of risk identified in the literature review: social and community impact; impact on sense of self; behavioural impact; and economic and educational impact. An additional section addresses combat sport experience and gender issues.

For the purposes of analysis and table content, the Likert questions were regularised so that in all cases below, a score of 1 is the strongest possible agreement with a statement and a score of 7 is the strongest possible disagreement. The overall mean for all Likert statements was 2.3, indicating that respondents felt combat sport participation had had a generally positive impact on their lives regarding a reduced risk of offending.

\section{Social and community impact}

Participants responded to four key statements (see Table 6), with two additional questions measuring the extent to which combat sport has changed their social life and how. The mean response to the four

Table 6: Community and social impact

\begin{tabular}{lccc}
\hline & $N$ & Mean & $\begin{array}{l}\text { Std. } \\
\text { deviation }\end{array}$ \\
\hline $\begin{array}{l}\text { Effect on family } \\
\text { relationships }\end{array}$ & 50 & 1.5 & 1.111 \\
$\begin{array}{l}\text { Peer influence of other } \\
\text { participants }\end{array}$ & 50 & 1.58 & 1.43 \\
$\begin{array}{l}\text { Effect on relationships } \\
\text { with friends }\end{array}$ & 50 & 1.68 & 1.316 \\
$\begin{array}{l}\text { Feel part of the } \\
\text { community }\end{array}$ & 50 & 2.22 & 1.502 \\
\hline
\end{tabular}


key statements was 1.7, indicating that participants perceive themselves to have fostered stable relationships with family and non-deviant friends and are more included in the community, since participating in combat sport.

Participants' responses overall, to statements about the impact of combat sport on relationships with family and friends, achieved a mean score of 1.5 and 1.68 respectively (see Table 6). Additionally, the statements encountered 80 per cent and 72 per cent maximum agreement respectively. The implication is that large proportions of participants could have experienced a strengthening of family and friend relationships as a result of involvement in combat sports. The peer effect of other participants was seen as a positive influence on their behaviour, with a mean response of 1.58 (see Table 6) with 80 per cent of the sample responding with maximum agreement, indicating that the social life at the training facility positively influences many participants.

Regarding the extent to which participants' social lives had changed, the mean response of 2.22 shows that 72 per cent of participants believe that combat sports have changed their social life. When asked to expand, 60 per cent of participants highlighted gaining a combat sport-specific social life, with other members in and out of training. Considering that the majority of participants believed club members to be a positive influence, their increased involvement in one another's social lives should be considered constructive.

\section{Impact on sense of self}

This small but important section was based on responses to two statements and one question qualifying the impact of combat sport participation on self-esteem. Participants considered combat sports to be a highly important part of their identity and a positive impact on self-esteem acquiring mean
Table 7: Impact on sense of self

\begin{tabular}{|c|c|c|c|}
\hline & $N$ & Mean & $\begin{array}{l}\text { Std. } \\
\text { deviation }\end{array}$ \\
\hline $\begin{array}{l}\text { Forms part of a proud } \\
\text { identity }\end{array}$ & 50 & 1.78 & 1.055 \\
\hline Changed self-esteem & 50 & 2.1 & 1.266 \\
\hline
\end{tabular}

responses of 1.78 and 2.1 respectively (see Table 7). The qualitative responses showed that 42 per cent of respondents cited increased confidence since participating in combat sports, as the reason for increased self-esteem.

\section{Behavioural impact}

Participants were asked to comment on four statements evaluating the impact of combat sport participation on their behaviour (see Table 8). There were also two qualitative questions for explanation and one question measuring the extent of changes in conflict resolution (see Table 8 'makes me deal with conflict differently'). The overall mean for responses to the four behavioural statements was a positive 2.2 , indicating that respondents believed that combat sport participation has helped them control

Table 8: Behavioural impact

\begin{tabular}{lccc}
\hline & $N$ & Mean & $\begin{array}{l}\text { Std. } \\
\text { deviation }\end{array}$ \\
& & & \\
\hline $\begin{array}{l}\text { Makes me less violent/ } \\
\text { aggressive toward others }\end{array}$ & 50 & 1.66 & 1.189 \\
$\begin{array}{l}\text { Helps me cope with } \\
\text { stress }\end{array}$ & 50 & 2.08 & 1.322 \\
$\begin{array}{l}\text { Less likely to engage in } \\
\text { violent assault }\end{array}$ & 50 & 2.54 & 2.002 \\
$\begin{array}{l}\text { Less likely to engage in } \\
\text { drug abuse }\end{array}$ & 50 & 2.66 & 2.086 \\
$\begin{array}{l}\text { Makes me deal with } \\
\text { conflict differently }\end{array}$ & 50 & 2.9 & 1.876 \\
\hline
\end{tabular}


aggressive/violent behaviours, deal better with stress, and be less likely to commit violent assault or use controlled substances.

The violence and aggression statement's mean response of 1.66 (see Table 8) indicates that the sample of respondents feel that they have not been made more violent or aggressive by participating in combat sport. Furthermore, 62 per cent of the sample experienced a possible reduction in perceived violent and aggressive behaviour since participating.

When asked if they were less likely to engage in violent assault $(M=2.54)$ and drug abuse $(M=2.66)$ the positive responses indicate that the respondents perceived their risk of engagement in these activities had decreased. However, when asked to offer a reason, 24 per cent of the sample failed to comment. The 38 participants who responded showed that the primary reason was increased self-control since participating in combat sport (26.3 valid per cent). However, the second highest response indicated that combat sport participation had no impact on the perceived likelihood of engagement in the offences for many participants. When coupled with the lack of response, it was not possible to be certain whether combat sport participation materialises into reductions in violent and drug-related offences.

Participants felt that they dealt with conflict differently since participating in combat sports, with a mean of 2.9 (see Table 8). When asked to expand, 44 participants highlighted two common themes: increased self-control (30 per cent); and increased confidence in their ability to deal with conflict (22 per cent).

\section{Economic and educational impact}

Participants responded to five statements (and expanded on two) on economic and educational impact (see Table 9). With a mean of 3.0, the sample perceived combat sports to have: improved work and
Table 9: Economic and educational impact

\begin{tabular}{lccc}
\hline & $N$ & Mean & $\begin{array}{l}\text { Std. } \\
\text { deviation }\end{array}$ \\
\hline $\begin{array}{l}\text { Improved work/leisure } \\
\text { relationship }\end{array}$ & 50 & 2.64 & 1.467 \\
$\begin{array}{l}\text { Distraction effect on } \\
\text { important tasks }\end{array}$ & 50 & 2.92 & 1.816 \\
$\begin{array}{l}\text { Improved education/ } \\
\text { leisure relationship }\end{array}$ & 46 & 3.17 & 1.387 \\
$\begin{array}{l}\text { Helps do better in } \\
\text { education }\end{array}$ & 49 & 3.24 & 1.575 \\
$\begin{array}{l}\text { Helps do better at work } \\
\text { Melp }\end{array}$ & 50 & 3.28 & 1.703 \\
\hline
\end{tabular}

educational/leisure balance; mildly improved performance; and not distracted them from completing important economic and educational functions (see Table 9).

The work/leisure relationship statement received a positive mean response of 2.64 (see Table 9). Further analysis revealed that despite an 18 per cent neutral response, 74 per cent of the sample perceived themselves to have experienced improvements in their work/leisure relationship. The two key reasons offered were that combat sports allowed participants to relax (26 per cent) and allowed a healthier lifestyle through increased energy (14 per cent).

Large proportions of the sample took a neutral stance (48 per cent) or failed to respond ( 8 per cent) to the statement regarding education/leisure relationship which makes a conclusive finding difficult. However, when asked to expand, 18 per cent of the sample cited an increased level of focus since participating in combat sport, helping them balance leisure and education better.

The results for educational and economic effects did yield some pronounced positive influences. For example, 68 per cent believed that combat sports did not distract them from important tasks. This indicates that combat sport participation possibly 
helped them to focus on important economic and educational tasks. Furthermore, even with a 34 per cent neutral response, 52 per cent of the sample $(N=50)$ felt that combat sports 'helps them do better at work'. The same question was applied to education $(N=49)$ with similar results $(28$ per cent neutral response and 54 per cent positive response).

\section{Extent of experience of combat sport}

'Experience' was characterised by: hours per week; number of years participating in the current combat sport; and number of alternative combat sports experienced. A moderately negative correlation $(r=$ -0.241) was discovered between hours training per week and the mean extent of impact. This indicates that participants with a greater level of involvement perceive combat sport to have had a greater impact on their life (see Table 10).

A moderately negative correlation $(r=$ -0.258 ) was discovered between experience in the current combat sport and the mean perceived nature of impact. This indicates that the longer participants stayed connected to the combat sport club, the more positive they perceived its impact to be.

No correlation was found between weekly participation (hours), experience in the current combat sport (years), or the number of combat sports participated in, and the perceived extent of impact. Furthermore, the research indicates that the number of combat sports participated in

Table 10: Weekly participation and extent of impact

\begin{tabular}{ll}
\hline Weekly participation (hrs) & Mean extent of impact \\
\hline$<2$ & 3.2 \\
$>2-<6$ & 2.6 \\
$>6-<10$ & 2.1 \\
$>10$ & 1.5 \\
\hline
\end{tabular}

does not alter the respondents' perceived nature of impact.

\section{Gender}

Importantly, there were no significant differences between males' and females' responses in any aspect of the study, with equally positive general means for all Likert responses of 2.3 (males) and 2.1 (females). Similarly, the responses to statements measuring the extent of combat sport impact attained mean scores of 2.5 for both males and females.

\section{DISCUSSION}

The existing literature and evidence revealed an explicit, mostly positive relationship between socio-cultural risk factors and leisure/sports-based offender programmes. This research has sought to extend the examination of this relationship to participation in combat sports.

The importance of non-deviant social networks appears in much of the existing literature (Loxley et al., 2002; Mahoney, 2000; Nichols, 1997; Nichols \& Crow 2004). As such, many of the community crime reduction strategies and sport-based interventions include the use of groupbased activities to develop pro-social relationships. Our findings suggest that combat sport participation can strengthen relationships with family and friends and provide participants with non-deviant peer networks. This represents a reduction in the exposure to risk factors associated with the community. The combat sports we studied are not team sports, but they appear to provide a similar encouraging and supportive atmosphere to that encountered in boxing clubs studied by Wright (2006). Based on these results, the use of combat sports could be recommended for interventions aimed at group offenders, such as gang members, or as a pre-emptive attempt to 
reduce the community and social risk factors experienced by individuals lacking the support of the family unit. Given the lack of combat sports-based interventions, these benefits appear to have been neglected by the Ministry of Justice and the National Offender Management Service in England and Wales.

Connected with the fostering of nondeviant peer networks is the issue of selfesteem. Both have been categorised by Nichols and Crow $(2004$, p. 270) under the umbrella of pro-social developments. This leads to a consideration of the impact of combat sport participation on an individual's sense of self. A striking finding from our research is that combat sport forms an important part of the participants' identities with which they are proud to be affiliated. In turn, combat sports increased the selfesteem of participants through increased self-confidence. Fletcher (as cited in Nichols, 1997, p.184) and Wright (2006, pp.154-164) also discovered increased selfesteem among boxing participants. The main question is how this change reduces crime. Nichols and Crow (p.169) argue that self-esteem increases as individuals spend more time with appropriate role models and non-deviant peers. In turn, they no longer feel the need to engage in imageboosting antisocial behaviours. Considering the perceived social and community benefits that combat sport has provided our respondents (the current sample), it appears to support Nichols and Crow's argument. The implication is that the combat sports could be used within crime reduction strategies aimed at moderating antisocial behaviour by countering the risk factors affecting an individual's sense of self.

Previous studies suggest that participation in combat sports can act as a moderator for behavioural problems associated with offending by: reducing aggressive temperament (Palermo et al., 2006; Trulson, 1986; Wright, 2006); aiding individuals to cope better with stress (Wright); reducing instances of assault and drug abuse (Fletcher, as cited in Nichols, 1997, p. 184; Nichols, 1997; Coalter; and Elias \& Dunning, both studies as cited in Smith \& Waddington, 2004, p. 284); and enabling individuals to control emotions in conflict situations (Fletcher; Palermo et al.; Wright). The implication is that these changes in behaviour could represent distancing from the behavioural risk factors highlighted by Anderson et al. (2005, p. 4), such as aggressiveness and disobedience (Palermo et al., p. 654).

Expanding sports-based programmes can also reduce crime by meeting the excitement needs, usually gained by committing crime or using controlled substances (Nichols, 1997, p.183; Coalter; and Elias \& Dunning, both studies as cited in Smith \& Waddington, 2004, p. 284). This effect would be increased if the excitement gained from the participation matched elements of risk involved in offending. Thus, introducing elements of danger, such as the risk involved in combat sports, could be beneficial to sports-based programmes. The same is to be said of the long-term personal development and pro-social development, since crucial elements are increased selfcontrol, self-esteem and self-discipline. In summary, one could argue that combat sports-based interventions would potentially be ideal for addressing behavioural risk factors, and targeting violent and emotionally impulsive offenders.

Evidence provided by the current research shows that combat sport participation can improve educational and economic performance (Loxley et al., 2002; Mahoney, 2000; Nichols, 1997; Nichols \& Crow, 2004); and improve work/leisure relationships. Furthermore, evidence suggests that improvements in the participants' behavioural risk factors contribute to protection from economic risk factors. Our research 
suggests that the primary reason for educational and economic improvement was increased relaxation. When coupled with the perceived stress relief benefits of combat sport participation, it is possible to argue that behavioural improvements had a positive impact on economic risk factors. Nichols and Crow; Nichols; and Loxley et al. all argued that improved cognitive development can lead to employment through sport-based programmes. Therefore, the use of combat sport participation within training, education and employment intervention schemes could result in long-term crime-reduction benefits. However, in this study, we could not address the extent to which improved work/leisure relationships or work performance materialise into real economic advantage such as increased opportunities, income and qualifications.

Similar difficulty is encountered when discussing educational improvements which are confined primarily to combat sports as a use of leisure time. For Mahoney and Stattin (2000, p. 123) and Mahoney et al. (2001, p. 509) constructive leisure time is participation in structured events such as team sports. Unconstructive leisure includes low structure groups, such as those encountered at youth recreation centres. The participating combat sports clubs used high levels of structure and hierarchy, making them consistent with a constructive use of leisure time. This would make participants less likely to drop out of education and offend (Mahoney, 2000, pp. 512-513). Our study could not include youths under 16 years of age and more research is needed before being able to make an empirically grounded recommendation regarding the crime reduction benefits of combat sports, through improved educational performance. We can suggest that our adult respondents felt that combat sport participation had reduced their exposure to economic and educational risk factors. However, economic improvements relate more to reduced behavioural risk factors and the structure of the activity.

\section{CONCLUSION}

Despite the limitations of the current research, this small but innovative study has successfully evaluated the impact of combat sport participation on individual criminality.

It has shown that combat sport participation can act as a protective factor which distances participants from socio-cultural and individual risk factors in the behavioural, economic and social spheres. It has shown that combat sport represents an appropriate activity to be utilised within crime reduction strategies that aim to address these risks. Furthermore, it has indicated that combat sport has the potential to help treat violent offenders, gang/group offenders and emotionally charged impulsive offenders.

It does not, however, prove decisively that combat sport will rid participants of any risk that they might offend. There are more complex structural risk factors that combat sports cannot address for which more extensive, representative and controlled longitudinal research is required, if one is to fully understand the impact of combat sport participation.

We feel this study provides a clear indication that the 'what works' agenda cannot be considered complete whilst combat sport continues to show significant potential to be examined in more detail. A larger study is required that can address the following issues. First, the reliability of respondents' perceived impact of combat sports needs to be measured against actual behaviour. Thus, future research would benefit from using more objective measurements such as reoffending/reconviction rates and additional psychological behavioural instruments. Second, the sample consisted of individuals who voluntarily participate in 
regular combat sports and there is therefore a need for an evaluation within the context of offender treatment programmes. It is likely that combat sport would still be subject to offender self-selection, as coerced participation would not only be ethically and politically unpalatable, but would work against 'what works' selection criteria. Third, our research is effectively a small, innovative pilot study and needs to be expanded to incorporate a much larger sample, including proportionate sampling of women and children. Finally, but most importantly, future research should include a control or comparison group of noncombat sports participants.

\section{References}

Abbot, B., \& Barber, B. (2007). Not just idle time: adolescents' developmental experiences provided by structured and unstructured leisure activities. Australian Educational and Developmental Psychologist, 24(1), 59-81.

Anderson, B., Beinart, S., Farrington, D., Langman, J., Sturgis, P., \& Utting, D. (2005). Risk and protective factors. Youth Justice Board.

Astbury, R., Knight, B., \& Nichols, G.. (2005). The contribution of sport-related interventions to the long-term development of disaffected young people: an evaluation of the Fairbridge program. Journal of Park and Recreation Administration, 23(3), 82-98.

Davies, G. (2008, 18 January) UFCs Are Here To Stay. Retrieved 27 March 2011 from http://blogs.telegraph.co.uk/sport/garetha davies/3665421/UFCs_are_here_to_stay/

Dunning, E. (2005). Violence and sport. In W. Heitmeyer \& J. Hagan (Eds.), The international handbook of violence research (pp. 903-920). Dordrecht, Holland: Kluwer Academic Publishers.

Endresen, I., \& Olweus, D. (2005). Participation in power sports and antisocial involvement in preadolescent and adolescent boys. Journal of Child Psychology and Psychiatry, 46(5), 468-478.
Forbes, G., Adams-Curtis, L., Pakalka, A., \& White, K. (2006). Dating aggression, sexual coercion, and aggression-supporting attitudes among college men as a function of participation in aggressive high school sports. Violence Against Women, 12(5), 441-455.

Hartmann, D., \& Depro, B. (2006). Rethinking sports-based community crime prevention: a preliminary analysis of the relationship between Midnight Basketball and urban crime rates. Journal of Sport and Social Issues, 30, 180-196.

Haynes, C., Rife, E., \& Laguna, L. (2005). The impact of a summer camp program as a secondary prevention measure for at-risk youth. Crime Prevention and Community Safety: An International Journal, 7(3), 37-49.

Home Office. (1997). No more excuses: a new approach to tackling youth crime in England and Wales (Cm. 3809). London: HMSO.

Hurry, J., \& Moriarty, V. (2004). Education, training and employment projects: the national evaluation of the Youth Justice Board's education, training and employment projects. London: Youth Justice Board.

Koss, M., \& Gaines, J. (1993). The prediction of sexual aggression by alcohol use, athletic participation, and fraternity affiliation. Journal of Interpersonal Violence, 8(1), 94-108.

Loxley, C., Curtin, L., \& Brown, R. (2002). Summer Splash schemes 2000: findings from six case studies (Crime Reduction Research, series paper 12). London: Home Office.

Mahoney, J. (2000). School extracurricular activity participation as a moderator in the development of antisocial patterns. Child Development, 71(2), 502-516.

Mahoney, J., \& Stattin, H. (2000). Leisure activities and adolescent antisocial behaviour: the role of structure and social context. Journal of Adolescence, 23, 113-127.

Mahoney, J., Stattin, H., \& Magnusson, D. (2001). Youth recreation centre participation and criminal offending: a 20-year longitudinal study of Swedish boys. International Journal of Behavioural Development, 25(6), 509-520.

Meak, R. (2006). Social deprivation and rural youth crime: young men in prison and 
their experiences of the 'rural idyll'. Crime Prevention and Community Safety, 8, 90-103.

Metropolitan Police Service. (n.d.). Youth boxing club is knockout. Retrieved 16 February 2009, from http://cms.met.police. uk/met/boroughs/barking_and_dagenham/ 04how_are_we_doing/news/youth_ boxing_club_is_a_knockout

Muncie, J. (1999). Institutionalized intolerance: youth justice and the 1998 Crime and Disorder Act. Critical Social Policy, 19, 147-175.

Neighbourhood Renewal Unit. (2003). Joint working in sport and neighbourhood renewal (Report 9). London: Office of the Deputy Prime Minister.

Nichols, G.. (1997). A consideration of why active participation in sport and leisure might reduce criminal behaviour. Sport, Education and Society, 2(2), 181-190.

Nichols, G., \& Crow, I. (2004). Measuring the impact of crime reduction interventions involving sports activities for young people. Howard Journal, 43(3), 267-283.

Palermo, M., Di Luigi, M., Dal Forno, G., Dominici, C., Vicomandi, D., Sambucioni, A., et al. (2006). Externalizing and oppositional behaviours and Karate-do: the way of crime prevention: a pilot study. International Journal of Offender Therapy and Comparative Criminology, 50, 654-660.

Smith, A., \& Waddington, I. (2004). Using 'sport in the community schemes' to tackle crime and drug use among young people: some policy issues and problems. European Physical Education Review, 10, 279-298.

Sport England. (n.d.a). Active England case studies. Retrieved 8 January 2010, from http://www.sportengland.org/search.aspx? query $=$ neighbourhood + renewal + unit

Sport England. (n.d.b). The value of sport monitor. Retrieved 17 April 2011, from http://www.sportengland.org/research/ value_of_sport_monitor.aspx

Sport England. (1999). Best Value through sport: the value of sport to local authorities. Retrieved 27 March 2011 from http://www.toolkit sportdevelopment.org/html/resources/5C/ 5C6D9742-7A45-4906-A1E3-0B7132A 89051/best\%20value\%20through\%20 sport $\% 20$ authorities.pdf

Sport England. (2005). Spatial planning for sport and active recreation, guidance on Sport England's aspirations and experience v1.0. Retrieved 8 January 2010, from http:// www.sportengland.org/search.aspx?query =neighbourhood + renewal+unit

Trulson, M. (1986). Martial arts training: a novel 'cure' for juvenile delinquency. Human Relations, 39, 1131-1140.

Woods, R. (2007). Social issues in sport. Champaign, IL: Human Kinetics.

Wright, W. (2006). Keep it in the ring: using boxing in social group work with high-risk and offender youth to reduce violence. Social Work With Groups, 29(2), 149-174. 